\title{
A single nucleotide polymorphism located in microRNA-499a causes loss of function resulting in increased expression of osbpl1a and reduced serum HDL level
}

\author{
LI-BO CHEN ${ }^{1}$, HAI-KUO ZHENG ${ }^{2}$, LEI ZHANG ${ }^{2}$, ZHE AN $^{2}$, \\ XIN-PENG WANG ${ }^{2}$, RUI-TING SHAN ${ }^{2}$ and WEN-QI ZHANG ${ }^{2}$ \\ Departments of ${ }^{1}$ Ultrasound and ${ }^{2}$ Cardiovascular Medicine, China-Japan Union Hospital \\ of Jilin University, Changchun, Jilin 130033, P.R. China
}

Received December 31, 2016; Accepted May 30, 2017

DOI: 10.3892/or.2017.6016

\begin{abstract}
Atherosclerosis is the main pathological process that induces CVD (cardiovascular diseases), and the objective of our study was explore whether miR-499a rs3746444 polymorphism was associated with the HDL level, one of the risk factors of atherosclerosis. Online public miRNA database was utilized to predict the miR-499a target, and luciferase assay was conducted to confirm that miR-499a targeted osbplla, then western blot analysis and real-time PCR were performed to verify miRNA-mRNA regulatory relationship between miR-499a and osbplla. Based on results of bioinformatics algorithms, osbplla was predicted as a candidate target gene of miR-499a, luciferase reporter was generated, and it was found that the luciferase activity of cells was substantial downregulated following co-transfection with wild osbpl1a 3'UTR and miR-499a compared to that in scramble control, while the inhibitory effect of miR-499a was abolished after transfection of mutant osbplla 3'UTR. Then, miRNA-mRNA regulatory relationship between miR-499a and osbplla was detected, a concentration-dependent effect of miR-499a on the miR-499a expression was observed, and both osbplla mRNA and protein levels of cells transfected with miR-449a (30 and $60 \mathrm{nM}$ ) or osbplla siRNA were markedly reduced, while notably improved subsequent to transfect with anti-miR-449a (30 and $60 \mathrm{nM}$ ) in comparison with $\mathrm{NC}$ groups, moreover, the inhibitory effect among 30 or $60 \mathrm{nM}$ miR-499a, osbplla siRNA was similar, the improved effect of 30 or $60 \mathrm{nM}$ anti-miR-499a showed no significant change. The influence of rs3746444 A allele on expression level of miR-499a represented a recessive pattern in high-grade group with a higher level of miR-499a
\end{abstract}

Correspondence to: Dr Wen-Qi Zhang, Department of Cardiovascular Medicine, China-Japan Union Hospital of Jilin University, 126 Xiantai Road, Changchun, Jilin 130033, P.R. China

E-mail: rs3746444hdl@yeah.net

Key words: single nucleotide polymorphism, microRNA-499a, osbplla, HDL, dyslipidemia in AA group, and HDL level in AA group was significantly reduced related to those in AG and GG groups. This study validated that rs 3746444 polymorphism influenced the expression of miR-499a, its target gene, osbpl1a, and thereby associated with the HDL level, which makes it a potential factor involved in the mechanism of atherosclerosis.

\section{Introduction}

Being a frequent pathological process, atherosclerosis underlies adverse cardiovascular events, such as coronary artery disorder, ischemic gangrene, abdominal aortic aneurisms and stroke (1). Clinical complications derived from atherosclerosis, including stroke and myocardial infarction are contributors to majority of the morbidity and mortality of cardiovascular disorders worldwide. There is still an unfulfilled need for nonstatin drugs for patients with normal levels of LDL-cholesterol and/or who are intolerant to statins or are maximized on current therapy although statin therapy has been demonstrated to significantly decrease mortality of cardiovascular diseases in patients with hypercholesterolemia (2).

OSBPL1A affects the target known as late endocytic compartments (LE) through the endoplasmic reticulum (ER) and the small GTPase Rab7 via VAMP-related proteins (VAPA and -B) (3). OSBPL1A acts as a sterol-specific regulator in the interactions between LE and ER membranes. OSBPL1A regulates the subcellular distribution and tethering and motility of the endosomes via the regulation of dynein/dynactin and homotypic fusion and protein sorting (HOPS) complexes and by linking the bridge between the ER and LE (4). The effect of OSBPL1A in lipid metabolism is not clear. In low-density lipoprotein receptor knock-out animals, overexpression of human OSBPL1A in mouse macrophages enhanced atherogenesis and disturbed cholesterol efflux to HDL (5).

As a family of small non-coding RNAs, microRNAs (miRNAs) bind to the 3 ' untranslated region (UTR) of target mRNAs to play a post-transcriptional regulatory role in gene expression. This causes the suppression of translation or the cleavage of the target mRNA by the Ago2 ribonuclease in the RNA-triggered silencing complex (RISC) (6). In addition, miRNAs can play their roles by regulation of the coordination 
between target mRNAs and effector instead of functioning as modulators of specific mRNAs (7). Deregulation of potential altered gene expression and miRNA expression may lead to the occurrence of cancerous phenotypes (8). Many microRNAs have been reported as having a role in the process of atherosclerosis (9). Here we highlight circulating miRNAs transported by LDL or HDL particles and briefly discusses circulating miRNAs identified to be implicated in intercellular interaction within atherosclerosis $(10,11)$. Circulating miRNA profiles have been demonstrated to vary in patients with hyperlipidemia and atherosclerosis $(12,13)$. Moreover, it was demonstrated that, compared with other portions of the genome, SNPs are less common in miRNAs or their target sites (14). This negative selection of sequence variations in miRNAs strengthens their significance for key cellular processes such as the modulation of gene expression. It is conceivable that the impact of miR-SNPs can be explained in different scenarios. On the one hand, SNPs in a miRNA-coding sequence might impact the expression of an array of different genes, for instance, because of a compromised maturation process or processing of the miRNA. On the other hand, SNPs in target sites can either regulate existing binding sites or build new binding sites to play their roles in one specific target molecule or in a few.

OSBPL1A has been demonstrated to play an important role in the metabolism of lipid, especially HDL, and it has been also shown that miR-499a targeted OSBPL1A $(15,16)$. One polymorphism in the pri-miR-499a has been reported to be able to compromise the processing the pri-miRNA and lower its production level (15). In this study, we validated the miR-499a/OSBPL1A involvement in HepG2 cells, and determined the correlation between the polymorphism of miR-499a rs3746444 and the expression of miR-499a, its target gene as well as its association with HLD level.

\section{Materials and methods}

Participants. Forty-eight subjects without health problems were collected at China-Japan Union Hospital of Jilin University, and peripheral blood samples were collected from these 46 subjects, and stored at $-80^{\circ} \mathrm{C}$ for prolonged storage for future use. The protocol of the study was approved by the Ethics Committee of China-Japan Union Hospital of Jilin University and written informed consents were obtained from all participants prior to the study.

Serum RNA isolation and real-time PCR. Serum samples frozen were thawed at room temperature, and Qiagen ${ }^{\circledR}$ miRNeasy kit (Qiagen ${ }^{\circledR} \mathrm{GmbH}$, Hilden, Germany) was utilized to extract total RNA from $500 \mu \mathrm{l}$ serum collected from the subjects according to the manufacturer's instructions. The PrimerScript RT reagent kit (Takara, Dalian, China) was used to perform the reverse transcription in $20 \mu \mathrm{l}$ of reaction volume, and the reaction was carried out at $37^{\circ} \mathrm{C}$ for $25 \mathrm{~min}$, then maintained at $85^{\circ} \mathrm{C}$ for $5 \mathrm{sec}$. ABI7500 (Applied Biosystems, Foster City, CA, USA) with SYBR Premix Ex Taq ${ }^{\mathrm{TM}}$ II (Takara) was used to perform real-time polymerase chain reaction with the cDNA synthesized. The reaction was carried out at $95^{\circ} \mathrm{C}$ for $30 \mathrm{sec}$ (initial denaturation), 40 cycles of $95^{\circ} \mathrm{C}$ for $5 \mathrm{sec}$ and $60^{\circ} \mathrm{C}$ for $30 \mathrm{sec}$ (amplification). The internal control included small nuclear
RNA U6 and $\beta$-actin. The cycle threshold $(\mathrm{Ct})$ value was used to express and analyze the relative miRNA-481 levels. $2^{-\triangle \Delta C T}$ (the comparative CT method) was used to present the expression of OSBPL1A gene and miR-499a. All reactions were performed in triplicate.

RNA isolation and real-time PCR.TRIzol ${ }^{\circledR}$ reagent (Invitrogen, NY, USA) was used to isolate total from HepG2 cells line and tissue samples according to the manufacturer's instructions. The PrimerScript RT reagent kit (Takara) was used to perform the reverse transcription in $20 \mu \mathrm{l}$ of reaction volume, and the reaction was carried out at $37^{\circ} \mathrm{C}$ for $25 \mathrm{~min}$, then maintained at $85^{\circ} \mathrm{C}$ for $5 \mathrm{sec}$. ABI7 500 (Applied Biosystems) with Premix Ex Taq II (Takara) was used to perform real-time polymerase chain reaction with the cDNA synthesized. The reaction was carried out at $95^{\circ} \mathrm{C}$ for $30 \mathrm{sec}$ (initial denaturation), 40 cycles of $95^{\circ} \mathrm{C}$ for $5 \mathrm{sec}$ and $60^{\circ} \mathrm{C}$ for $30 \mathrm{sec}$ (amplification). The internal controls were the small nuclear RNA U6 and $\beta$-actin. The cycle threshold $(\mathrm{Ct})$ value was used to express and analyze the relative miR-499a levels. $2^{-\Delta \Delta C T}$ was used to present the expression of OSBPL1A gene and miR-499a. All reactions were performed in triplicate.

Cell culture and transfection. RPMI-1640 (Roswell Park Memorial Institute) (Gibco, Grand Island, NY, USA) contained 10\% FBS (fetal bovine serum) (Gibco), $2 \mathrm{mM}$ glutamine (Sigma, USA) and 1\% streptomycin/penicillin was used to incubate the HepG2 cells at $37^{\circ} \mathrm{C}$ with $5 \% \mathrm{CO}_{2}$. miR-499a mimics and inhibitor were synthesized from RiboBio Co. (Guangzhou, China). In brief, the HepG2 cells seeded in 48-well plates at a concentration of $1 \times 10^{5}$ per well for $12 \mathrm{~h}$, Lipofectamine 2000 (Invitrogen, CA, USA) was used to transfect the cells with miR-499a mimics or inhibitor and OSBPL1A siRNA according to the manufacturer's instructions. Each was run three times.

Luciferase assay. PCR was performed to amplify OSBPL1A 3'UTR with putative miR-499a binding site from human genomic DNA purchased from Novagen (Madison, WI, USA), and mutation was introduced by using site-directed mutagenesis. Both wild-type and mutant 3'UTR of OSBPL1A were inserted into dual luciferase reporter vector (Promega, Madison, WI, USA) individually. Lipofectamine 2000 (Invitrogen) was used to co-transfect the HepG2 cells with $100 \mathrm{nM}$ wild-type/mutant type reporter construct and $50 \mathrm{nM}$ miR-499a mimic according to the manufacturer's instructions. Forty-eight hours after transfection, dual luciferase assay (Promega) was utilized to measure ratio of Renilla luciferase activity to firefly luciferase activity according to the manufacturer's instructions. All reactions were carried out three times.

Western blot analysis. The HepG2 cells were transfected with miR-499a mimics or inhibitor, and the cells were harvested $48 \mathrm{~h}$ after transfection, and ice-cold PBS buffer was used to wash the cells three times. RIPA (radioimmunoprecipitation assay) lysis buffer (Upstate Biotechnology, Lake Placid, NY, USA) was used to extract the protein from the HepG2 cells and tissue sample according to the manufacturer's instructions. The protein assay reagents (Bio-Rad Laboratories, Hercules, 


\section{A OSBPl1A 5' -AATTCTGAATTCTCACATTTT- 3' IIIIIIIII \\ Hsa-miR-499a 3' -UUAAGACUUGCAGUGAUGUUU- 5' HIIIII \\ OSBPL1A Mut 5' -AATTCTGAATTCTCACATTTT- 3'}

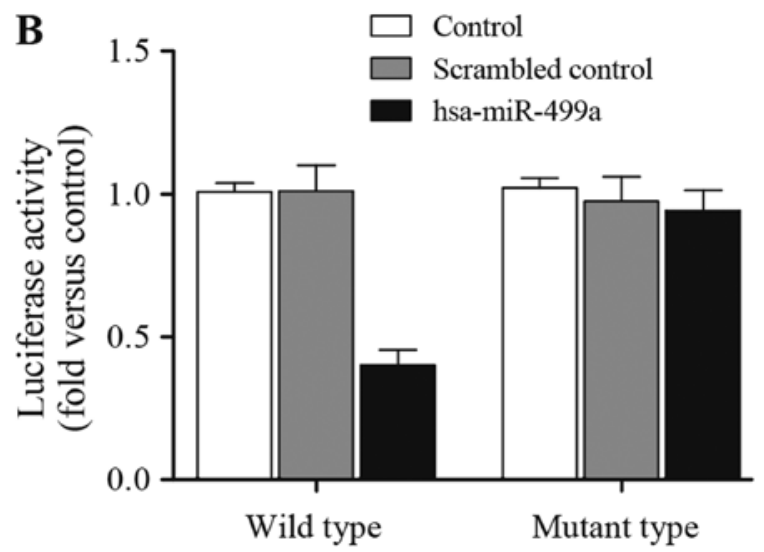

Figure 1. (A) Comparison between miR-499a and the wild-type (upper sequence)/mutated (lower sequence) 'seed sequence' in 3'UTR of osbpl1a. (B) Transfection of miR-499a significantly lowered the luciferase activity of the wild osbplla 3 'UTR compared with the scramble controls. While the luciferase activity of mutant osbplla 3'UTR in miR-499a overexpression cells was similar with scramble control.

CA, USA) was used to determine the protein concentration following the standard protocol. SDS-PAGE was used to separate the proteins, and then electro-transferred to a nitrocellulose membrane (Bio-Rad Laboratories), and Odyssey ${ }^{\circledR}$ blocking buffer (LI-COR Biosciences, Lincoln, NE, USA) was used to treat the membranes at room temperature for 60 min avoiding unspecific binding, then monoclonal mouse anti- $\beta$-actin antibody (1:10,000, Cell Signaling Technology, Inc., Beverly, MA, USA) and polyclonal rabbit anti-OSBPL1A antibody $(1: 5,000)$ (Cell Signaling Technology) were carried out to detect the target protein for $12 \mathrm{~h}$ at $4^{\circ} \mathrm{C}$, and the horseradish peroxidase $[(\mathrm{HRP})$-conjugated rabbit anti-goat $\mathrm{IgG}$ secondary antibodies (1:15,000, Cell Signaling Technology)] were used to visualize the bound antibodies for $2 \mathrm{~h}$ at room temperature. Odyssey CLx imaging system, model: Ody-3086 (LI-COR Inc.)

Statistical analysis. Each test was performed in triplicate. One-way ANOVA and Student's t-test were utilized to determine statistical significance, and Dunnett's multiple comparison tests was also performed to measure the statistical significance, and SigmaStat 3.1 software (Sigma-Aldrich, St. Louis, MO, USA) was utilized to perform the analyses. A value of $\mathrm{P}<0.05$ was considered to indicate a statistically significant difference.

\section{Results}

miR-499a directly targets osbplla. Bioinformatics algorithms including RNAhybrid and TargetScan were utilized to predict the miR-499a target gene. Based on the results of algorithms above, we predicted osbplla might be a possible target gene of miR-499a with a complementary seed region of miR-499a (Fig. 1A), then we mutated the seed region using site-directed mutagenesis, and obtained mutant type osbpl1a 3'UTR. To further confirm osbplla was a candidate gene of miR-499a, we then conducted luciferase assay, and subcloned wild or mutant osbpl1a 3'UTR into luciferase reporter which located directly downstream of luciferase gene. Then cells co-transfected with luciferase reporter carried wild or mutant osbplla 3'UTR and miR-499a or scramble control. As shown in Fig. 1B, the luciferase activity of cells co-transfected with wild osbplla 3'UTR and miR-499a was substantial downregulated compared to that in scramble control, while transfection of mutant osbplla 3'UTR abolished the inhibitory effect of miR-499a, indicated that miR-499a directly target osbplla 3'UTR, and repressed osbpl1a expression. As shown in Fig. 2, a single nucleotide polymorphism (rs3746444) in the miR-499a compromises the production of the miRNA.

miR-499a influences osbplla expression. Based on the results of in silico analysis and luciferase assay, osbplla was a virtual target gene of miR-499a, to further confirm the miRNAmRNA regulatory relationship between miR-499a and osbplla, we transfected HepG2 cells with various concentrations of miR-499a mimic (30 and $60 \mathrm{nM}$ ), anti-miR-499a mimic (30 and $60 \mathrm{nM}$ ), osbpl1a siRNA and negative control (NG), $\beta$-actin was used as internal control. Then miR-499a mRNA, osbplla mRNA and protein were examined using realtime PCR and western blot analysis. As shown in Fig. 3A, osbpl1a siRNA did not affect miR-499a level compared with NC group, the miR-499a level of cells treated with $30 \mathrm{nM}$ miR-499a mimics were apparently higher than the scramble control, and those of the cells treated with $60 \mathrm{nM}$ miR-499a mimics were even higher than the $30 \mathrm{nM}$ treatment group. As shown in Fig. 3B-D, both osbpl1a mRNA (Fig. 3B) and protein (Fig. 3C and D) levels of cells transfected with miR-449a

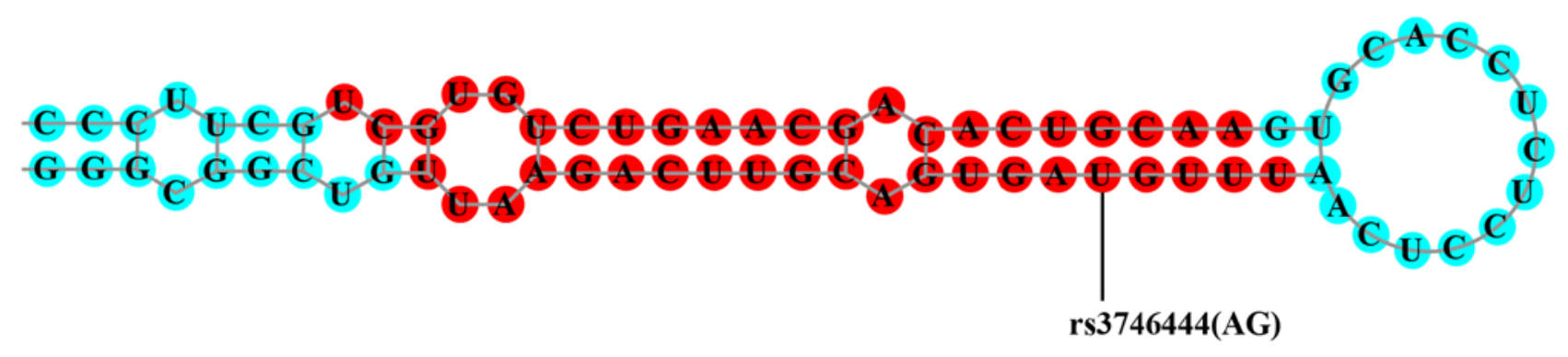

Figure 2. Rs3746444 in the miR-499a compromises the production of the miRNA. 

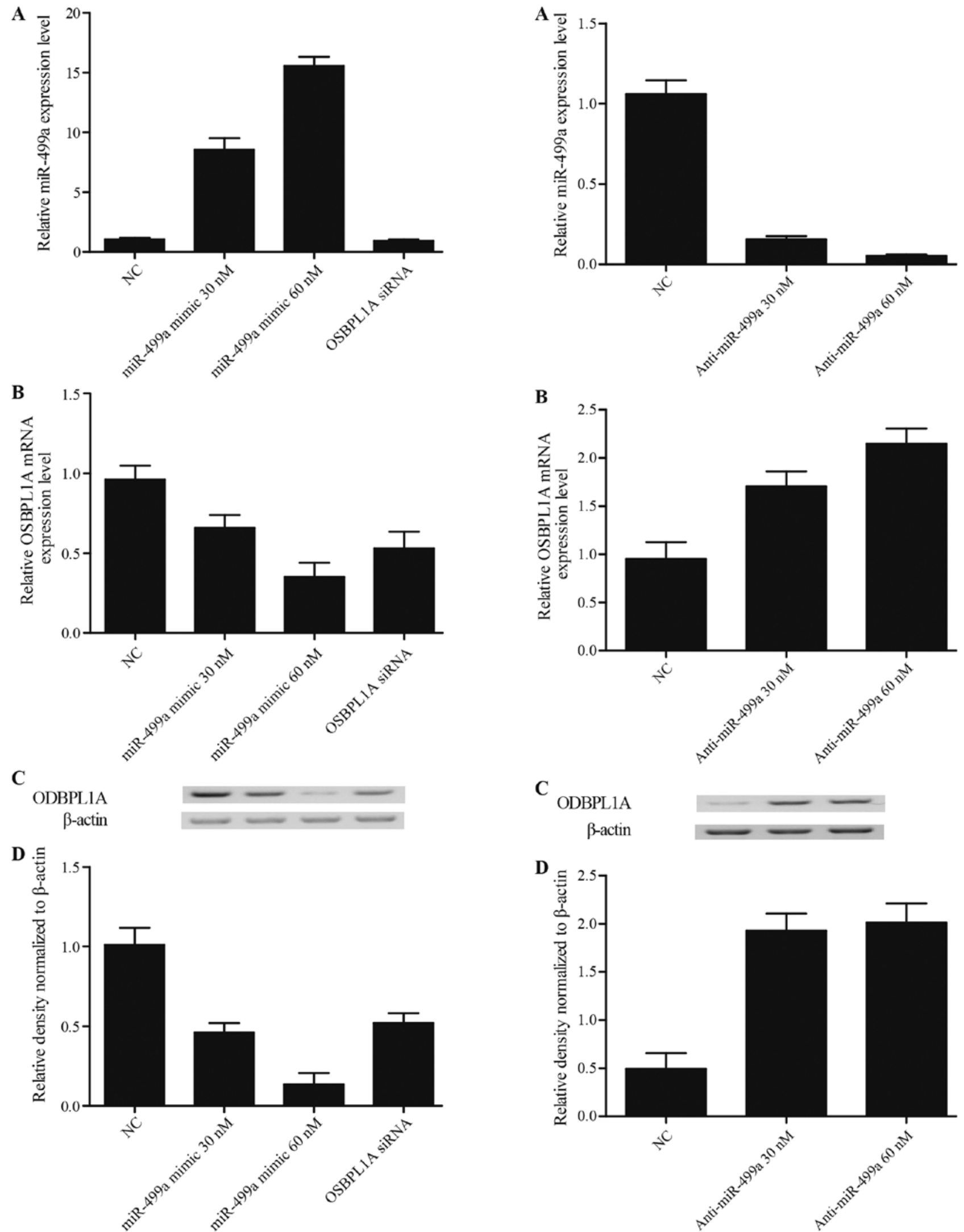

Figure 3. To confirm the miRNA-mRNA regulatory relationship between miR-499a and osbpl1a, HepG2 cells were transfected with different doses of miR-499a mimic ( 30 and $60 \mathrm{nM}$ ), osbplla siRNA and negative control (NG). (A) miR-499a mimic (30 and $60 \mathrm{nM}$ ) induced miR-499a expression in a dose-dependent manner. (B) miR-499a mimic (30 and $60 \mathrm{nM}$ ) and osbplla siRNA remarkably reduced osbplla mRNA expression. (C) miR-499a mimic (30 and $60 \mathrm{nM}$ ) and osbplla siRNA remarkably suppressed osbplla protein expression. (D) miR-499a mimic (30 and $60 \mathrm{nM})$ and osbplla siRNA remarkably lowered osbplla protein density.

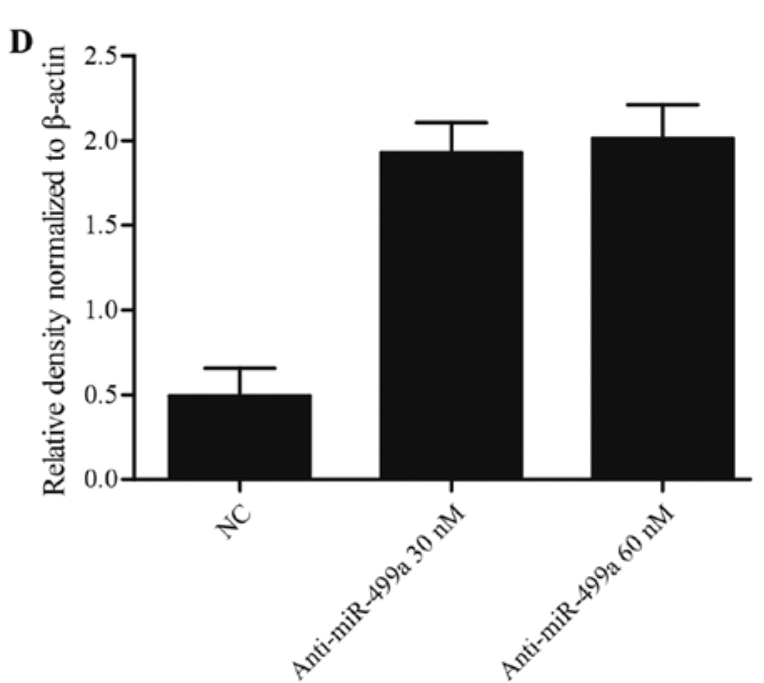

Figure 4. To confirm the miRNA-mRNA regulatory relationship between miR-499a and osbpl1a, HepG2 cells were transfected with different doses of anti-miR-499a mimic (30 and $60 \mathrm{nM})$ and negative control (NG). (A) Anti-miR-499a mimic (30 and $60 \mathrm{nM}$ ) inhibited miR-499a expression in a dose-dependent manner. (B) Anti-miR-499a mimic (30 and $60 \mathrm{nM}$ ) remarkably enhanced osbplla mRNA expression. (C) Anti-miR-499a mimic (30 and $60 \mathrm{nM}$ ) strikingly upregulated osbpl1a protein expression. (D) Anti-miR-499a mimic (30 and $60 \mathrm{nM}$ ) remarkably improved osbplla protein density. 

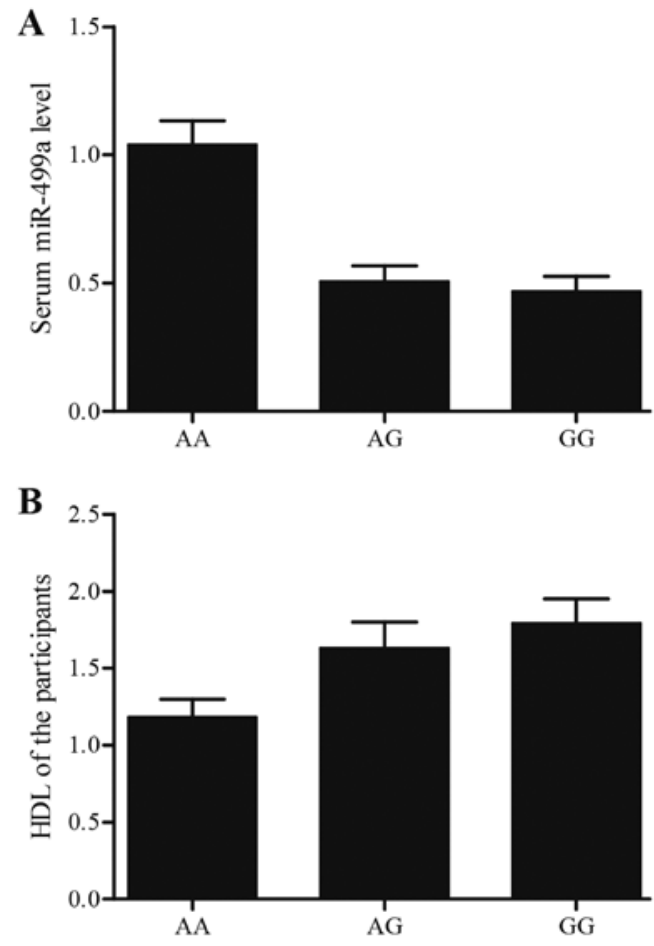

Figure 5. (A) miR-499a is highly expressed in AA group related to that in AG and GG groups. (B) Participants genotyped as AA displayed a much lower level of HDL.

(30 and $60 \mathrm{nM}$ ) or osbplla siRNA were markedly reduced in comparison with $\mathrm{NC}$ groups, furthermore the inhibitory effect of either $30 \mathrm{nM}$ miR-499a mimic or $60 \mathrm{nM}$ miR-499a mimic on osbpl1a expression was comparable with that of osbpl1a siRNA. By contrast, as shown in Fig. 4A, the miR-499a expression of cells treated with $30 \mathrm{nM}$ anti-miR-499a mimics and $60 \mathrm{nM}$ anti-miR-499a mimics were attenuated compared to the scramble control, and the suppression effect of $60 \mathrm{nM}$ anti-miR-499a mimic on miR-499a expression level was much stronger than $30 \mathrm{nM}$ anti-miR-499a mimic groups. As shown in Fig. 4B-D, both mRNA (Fig. 4B) and protein (Fig. 4C and D) levels of osbpl1a in cells transfected with anti-miR-449a (30 and $60 \mathrm{nM}$ ) were notably upregulated in comparison with NC groups, furthermore, the osbpl1a mRNA (Fig. 4B) and protein (Fig. 4C and D) in $30 \mathrm{nM}$ miR-499a mimic treatment group exhibited no obvious difference with $60 \mathrm{nM}$ miR-499a mimic treatment group, suggested that a concentrationdependent effect of miR-499a on the miR-499a expression, and miR-449a negatively regulated osbplla expression in a concentration-independent manner.

The expression of miR-499a and HDL level in different genotype groups. Forty-six volunteers diagnosed with atherosclerosis took part in our study. Also, information of participants, such as sex, age and HDL level were collected. To confirm the effect of rs 3746444 polymorphism on the expression of miR-499a, we divided the 46 participants into three groups by genotypes: $\mathrm{AA}, \mathrm{AG}$ and $\mathrm{GG}$, and the frequency distribution of the AA, AG, GG genotypes was 22,18 and 6 , respectively. Real-time quantitative PCR was performed to determine the level of miR-499a in serum derived from the 46 participants, as shown in Fig. 5A, miR-499a was overex- pressed in AA group compared with AG and GG groups, and miR-499a level in GA group and GG group was similar. The result validated that the influence of rs 3746444 A allele on expression level of miR-499a represented a recessive pattern in high-grade group. One-way ANOVA and Student's t-test were utilized to determine the difference on sex, age and HDL level among AA, AG and GG groups, as shown in Fig. 5B, HDL level in AA group was much lower than AG and GG groups, and sex or age in AA, AG and GG comparable with each other.

\section{Discussion}

Increasing data indicate that large amounts of MVs are released in human atherosclerotic plaques following the activation or apoptosis cells. Although the stimuli that mediate miRNA secretion are unclear (17). In addition, it has been shown that plaque MVs anchor on non-activated ECs and account for the development and progression of atherosclerosis (18). Particularly, patients with atherosclerosis have high levels of miR-499a-3p and miR-135b-5p (19). Hence, ECs might be a better option compared with VSMCs, because ECs have minimal expression of miR-499a-3p and miR-135-5p, and endothelial dysfunction is especially a driver in the mediation and progression of atherosclerosis (20). miR-499a is known as a potential AMI biomarker because the cardiac muscle has highly specific expression of miR-499a (21). The significant reduction (2.1-fold) in the production of miR-499a that we found in the AMI samples was evidenced by earlier studies that miR-499 is significantly increased in the serum of patients with AMI (indicator of release from the cardiac tissue) 4-12 h following AMI and is significantly reduced in the zone with cardiac infarction in an AMI mouse model $(22,23)$. In this study, we used online miRNA target prediction tools to search the target gene of miR-499a, and found that osbplla might be a possible target gene of miR-499a with a complementary seed region of miR-499a located within osbplla 3'UTR. Next, we conducted luciferase reporter assay to validate osbplla as a direct target gene of miR-499a.

As a member of a family of sterol sensors, the gene known as OSBPL1A could have an effect on lipid metabolism (24). It is thought that epigenetic modification has another critical role involving nutrient sensing (25). OSBPL1A is present at $20 \mathrm{~kb}$ from the imprinted gene IMPACT, however, mouse brain does not show an imprinted gene (26). Our screen identified the second new imprinted gene known as oxysterol-binding protein-like 1A (OSBPL1A), encoding an oxysterol-binding protein, a family involving in an array of metabolic processes (27). Previously, OSBPL1A has been linked to the cellular cholesterol homeostasis as demonstrated in cases of knockdown and overexpression of the protein. In transgenic mice with overexpression of human OSBPL1A under scavenger receptor A promoter, a defect of cholesterol efflux from cholesterol-loaded macrophages to HDL particles was found (5). The role of OSBPL1A has so far not been investigated in the intestine, the liver and tissues attributable to bulk HDL biogenesis (28). Nevertheless, the described functional relations with cholesterol efflux to HDL or apoA-I reveal that OSBPL1A, which is produced in the intestine (http://biogps. org/) and liver, is possibly a contributor to the secretion and/ 
or biogenesis of HDL particles $(29,30)$. In this study, we performed real-time quantitative PCR and western blot analysis to further validate the miRNA-mRNA regulatory relationship between miR-499a and osbplla, and found that osbplla siRNA could not affect the miR-499a level, and miR-499a enhanced miR-499a expression in a concentrationdependent manner. Moreover, both mRNA and protein levels of osbplla in cells transfected with miR-449a (30 and $60 \mathrm{nM}$ ) or osbplla siRNA were remarkably down-regulated compared to NC groups, furthermore the inhibitory effect of either $30 \mathrm{nM}$ miR-499a mimic or $60 \mathrm{nM}$ miR-499a mimic on osbplla expression was similar with that of osbplla siRNA, on the contrary both mRNA and protein levels of osbplla were notably upregulated in miR-499a low-expression cells by transfecting with anti-miR-449a (30 and $60 \mathrm{nM}$ ) compared to $\mathrm{NC}$ groups, and the osbplla mRNA and protein in $30 \mathrm{nM}$ miR-499a mimic treatment group was comparable with $60 \mathrm{nM}$ miR-499a mimic treatment group.

Changes in the expression of miRNA genes are believed to account for the pathogenesis of stroke, such as edema formation, inflammation, oxidative damage, neuronal cell death, diabetes mellitus, hypertension and atherosclerosis (31). miRNAs may be new biomarkers for cardiovascular disorders such as high blood pressure, stroke, diabetes mellitus and coronary artery disease (32-35). In a Chinese population (391 healthy subjects and 296 ischemic stroke patients), Liu and colleagues analyzed three SNPs and observed that the frequency of the allele G of hsa-mir-499/rs3746444 was significantly related to ischemic stroke. miR-499 and miR-196a2 modulated CRP and Annexin A1, which are also the common contributors to cerebral ischemia and related to increased triglycerides, insulin resistance, BMI and blood pressure (36-39). Although Liu et al reported that miR-499 G allele was significantly associated with increased risk of ischemic stroke in Chinese population, we found that miR-499/ rs3746444 and miR-196a2/rs11614913 were not related to ischemic stroke in this study (40). These two SNPs have also been extensively investigated in other human disorders, such as cancer, coronary heart disease and congenital heart disease (41-43). An earlier experiment revealed that the high serum level of miR-499A $>$ G was significantly correlated with a longer survival of non-small cell lung cancer, and that miRNA plays a role in tumor biology and is correlated with the development and prognosis of cancer (44). Typical single nucleotide polymorphisms in pre-miRNA, rs2910164 in miR-146aG $>C$ and rs3746444 in miR-499A $>\mathrm{G}$, have been investigated in a variety of cancers, such as colorectal cancer, cervical squamous cell cancer, gastric cancer and breast cancer $(45,46)$. In this study, we collected 46 participants with atherosclerosis to explore the effect of rs 3746444 polymorphism on the expression of miR-499a, and found that miR-499a was overexpressed in AA group compared with AG and GG groups, and also performed one-way ANOVA analysis, and revealed that HDL level in AA group was much lower than AG and GG groups.

In conclusion, the findings of this study demonstrated that rs3746444 polymorphism influenced the expression of miR-499a, its target gene, osbplla, and thereby associated with the HDL level, making it a potential factor involved in the mechanism of atherosclerosis.

\section{References}

1. Lloyd-Jones D, Adams R, Carnethon M, De Simone G, Ferguson TB, Flegal K, Ford E, Furie K, Go A, Greenlund K, et al; American Heart Association Statistics Committee and Stroke Statistics Subcommittee: Heart disease and stroke statistics - 2009 update: A report from the American Heart Association Statistics Committee and Stroke Statistics Subcommittee. Circulation 119: e21-e181, 2009.

2. Davidson MH: Novel nonstatin strategies to lower low-density lipoprotein cholesterol. Curr Atheroscler Rep 11: 67-70, 2009.

3. Johansson $M$, Lehto $M$, Tanhuanpää $K$, Cover TL and Olkkonen VM: The oxysterol-binding protein homologue ORP1L interacts with Rab7 and alters functional properties of late endocytic compartments. Mol Biol Cell 16: 5480-5492, 2005.

4. van der Kant R, Fish A, Janssen L, Janssen H, Krom S, Ho N, Brummelkamp T, Carette J, Rocha N and Neefjes J: Late endosomal transport and tethering are coupled processes controlled by RILP and the cholesterol sensor ORP1L. J Cell Sci 126: 3462-3474, 2013.

5. Yan D, Jauhiainen M, Hildebrand RB, Willems van Dijk K, Van Berkel TJ, Ehnholm C, Van Eck M and Olkkonen VM: Expression of human OSBP-related protein $1 \mathrm{~L}$ in macrophages enhances atherosclerotic lesion development in LDL receptordeficient mice. Arterioscler Thromb Vasc Biol 27: 1618-1624, 2007.

6. He L and Hannon GJ: MicroRNAs: Small RNAs with a big role in gene regulation. Nat Rev Genet 5: 522-531, 2004.

7. Dvinge H, Git A, Gräf S, Salmon-Divon M, Curtis C, Sottoriva A, Zhao Y, Hirst M, Armisen J, Miska EA, et al: The shaping and functional consequences of the microRNA landscape in breast cancer. Nature 497: 378-382, 2013.

8. Pillai RS: MicroRNA function: Multiple mechanisms for a tiny RNA? RNA 11: 1753-1761, 2005.

9. Madrigal-Matute J, Rotllan N, Aranda JF and FernándezHernando C: MicroRNAs and atherosclerosis. Curr Atheroscler Rep 15: 322, 2013.

10. Vickers KC, Palmisano BT, Shoucri BM, Shamburek RD and Remaley AT: MicroRNAs are transported in plasma and delivered to recipient cells by high-density lipoproteins. Nat Cell Biol 13: 423-433, 2011.

11. Fish JE, Santoro MM, Morton SU, Yu S, Yeh RF, Wythe JD, Ivey KN, Bruneau BG, Stainier DY and Srivastava D: miR-126 regulates angiogenic signaling and vascular integrity. Dev Cell 15: 272-284, 2008 .

12. Gao W, He HW, Wang ZM, Zhao H, Lian XQ, Wang YS, Zhu J, Yan JJ, Zhang DG, Yang ZJ, et al: Plasma levels of lipometabolism-related miR-122 and miR-370 are increased in patients with hyperlipidemia and associated with coronary artery disease. Lipids Health Dis 11: 55, 2012.

13. Karolina DS, Tavintharan S, Armugam A, Sepramaniam S, Pek SL, Wong MT, Lim SC, Sum CF and Jeyaseelan K: Circulating miRNA profiles in patients with metabolic syndrome. J Clin Endocrinol Metab 97: E2271-E2276, 2012.

14. Yu Z, Li Z, Jolicoeur N, Zhang L, Fortin Y, Wang E, Wu M and Shen SH: Aberrant allele frequencies of the SNPs located in microRNA target sites are potentially associated with human cancers. Nucleic Acids Res 35: 4535-4541, 2007.

15. Jeon YJ, Kim OJ, Kim SY, Oh SH, Oh D, Kim OJ, Shin BS and Kim NK: Association of the miR-146a, miR-149, miR-196a2, and miR-499 polymorphisms with ischemic stroke and silent brain infarction risk. Arterioscler Thromb Vasc Biol 33: 420-430, 2013.

16. Motazacker MM, Pirhonen J, van Capelleveen JC, WeberBoyvat M, Kuivenhoven JA, Shah S, Hovingh GK, Metso J, Li S, Ikonen E, et al: A loss-of-function variant in OSBPL1A predisposes to low plasma HDL cholesterol levels and impaired cholesterol efflux capacity. Atherosclerosis 249: 140-147, 2016.

17. Mallat Z, Hugel B, Ohan J, Lesèche G, Freyssinet JM and Tedgui A: Shed membrane microparticles with procoagulant potential in human atherosclerotic plaques: A role for apoptosis in plaque thrombogenicity. Circulation 99: 348-353, 1999.

18. Rautou PE, Leroyer AS, Ramkhelawon B, Devue C, Duflaut D, Vion AC, Nalbone G, Castier Y, Leseche G, Lehoux S, et al: Microparticles from human atherosclerotic plaques promote endothelial ICAM-1-dependent monocyte adhesion and transendothelial migration. Circ Res 108: 335-343, 2011.

19. Xu Z, Han Y, Liu J, Jiang F, Hu H, Wang Y, Liu Q, Gong Y and Li X: MiR-135b-5p and MiR-499a-3p promote cell proliferation and migration in atherosclerosis by directly targeting MEF2C. Sci Rep 5: 12276, 2015. 
20. Libby P: Inflammation in atherosclerosis. Nature 420: 868-874, 2002.

21. Kakimoto Y, Kamiguchi H, Ochiai E, Satoh F and Osawa M: MicroRNA stability in postmortem FFPE tissues: Quantitative analysis using autoptic samples from acute myocardial infarction patients. PLoS One 10: e0129338, 2015.

22. Deddens JC, Colijn JM, Oerlemans MI, Pasterkamp G, Chamuleau SA, Doevendans PA and Sluijter JP: Circulating microRNAs as novel biomarkers for the early diagnosis of acute coronary syndrome. J Cardiovasc Transl Res 6: 884-898, 2013.

23. Xiao J, Shen B, Li J, Lv D, Zhao Y, Wang F and Xu J: Serum microRNA-499 and microRNA-208a as biomarkers of acute myocardial infarction. Int J Clin Exp Med 7: 136-141, 2014.

24. Olkkonen VM, Johansson M, Suchanek M, Yan D, Hynynen R, Ehnholm C, Jauhiainen M, Thiele $C$ and Lehto $M$ : The OSBP-related proteins (ORPs): Global sterol sensors for co-ordination of cellular lipid metabolism, membrane trafficking and signalling processes? Biochem Soc Trans 34: 389-391, 2006

25. Jirtle RL and Skinner MK: Environmental epigenomics and disease susceptibility. Nat Rev Genet 8: 253-262, 2007.

26. Okamura K, Yamada Y, Sakaki Y and Ito T: An evolutionary scenario for genomic imprinting of Impact lying between nonimprinted neighbors. DNA Res 11: 381-390, 2004.

27. Jaworski CJ, Moreira E, Li A, Lee R and Rodriguez IR: A family of 12 human genes containing oxysterol-binding domains. Genomics 78: 185-196, 2001

28. Zannis VI, Fotakis P, Koukos G, Kardassis D, Ehnholm C, Jauhiainen $\mathrm{M}$ and Chroni A: HDL biogenesis, remodeling, and catabolism. Handb Exp Pharmacol 224: 53-111, 2015.

29. Johansson M, Bocher V, Lehto M, Chinetti G, Kuismanen E, Ehnholm C, Staels B and Olkkonen VM: The two variants of oxysterol binding protein-related protein-1 display different tissue expression patterns, have different intracellular localization, and are functionally distinct. Mol Biol Cell 14: 903-915, 2003.

30. Phillips MC: Molecular mechanisms of cellular cholesterol efflux. J Biol Chem 289: 24020-24029, 2014.

31. Tan JR, Koo YX, Kaur P, Liu F, Armugam A, Wong PT and Jeyaseelan K: microRNAs in stroke pathogenesis. Curr Mol Med 11: 76-92, 2011.

32. Li S, Zhu J, Zhang W, Chen Y, Zhang K, Popescu LM, Ma X, Lau WB, Rong R, Yu X, et al: Signature microRNA expression profile of essential hypertension and its novel link to human cytomegalovirus infection. Circulation 124: 175-184, 2011.

33. Tan KS, Armugam A, Sepramaniam S, Lim KY, Setyowati KD Wang CW and Jeyaseelan K: Expression profile of MicroRNAs in young stroke patients. PLoS One 4: e7689, 2009.

34. Zampetaki A, Kiechl S, Drozdov I, Willeit P, Mayr U, Prokopi M, Mayr A, Weger S, Oberhollenzer F, Bonora E, et al: Plasma microRNA profiling reveals loss of endothelial miR-126 and other microRNAs in type 2 diabetes. Circ Res 107: 810-817, 2010.
35. Fichtlscherer S, De Rosa S, Fox H, Schwietz T, Fischer A, Liebetrau C, Weber M, Hamm CW, Röxe T, Müller-Ardogan M, et al: Circulating microRNAs in patients with coronary artery disease. Circ Res 107: 677-684, 2010.

36. Yang B, Chen J, Li Y, Zhang J, Li D, Huang Z, Cai B, Li L, Shi Y, Ying B, et al: Association of polymorphisms in pre-miRNA with inflammatory biomarkers in rheumatoid arthritis in the Chinese Han population. Hum Immunol 73: 101-106, 2012.

37. Luthra R, Singh RR, Luthra MG, Li YX, Hannah C, Romans AM, Barkoh BA, Chen SS, Ensor J, Maru DM, et al: MicroRNA-196a targets annexin A1: A microRNA-mediated mechanism of annexin A1 downregulation in cancers. Oncogene 27: 6667-6678, 2008.

38. Solito E, McArthur S, Christian H, Gavins F, Buckingham JC and Gillies GE: Annexin A1 in the brain - undiscovered roles? Trends Pharmacol Sci 29: 135-142, 2008.

39. Wessel J, Moratorio G, Rao F, Mahata M, Zhang L, Greene W, Rana BK, Kennedy BP, Khandrika S, Huang P, et al: C-reactive protein, an 'intermediate phenotype' for inflammation: Human twin studies reveal heritability, association with blood pressure and the metabolic syndrome, and the influence of common polymorphism at catecholaminergic/beta-adrenergic pathway loci. J Hypertens 25: 329-343, 2007.

40. Liu Y, Ma Y, Zhang B, Wang SX, Wang XM and Yu JM: Genetic polymorphisms in pre-microRNAs and risk of ischemic stroke in a Chinese population. J Mol Neurosci 52: 473-480, 2014.

41. Xu J, Hu Z, Xu Z, Gu H, Yi L, Cao H, Chen J, Tian T, Liang J, Lin Y, et al: Functional variant in microRNA-196a 2 contributes to the susceptibility of congenital heart disease in a Chinese population. Hum Mutat 30: 1231-1236, 2009.

42. Hu Z, Chen J, Tian T, Zhou X, Gu H, Xu L, Zeng Y, Miao R, Jin G, Ma H, et al: Genetic variants of miRNA sequences and non-small cell lung cancer survival. J Clin Invest 118: 2600-2608, 2008.

43. Xiong XD, Cho M, Cai XP, Cheng J, Jing X, Cen JM, Liu X, Yang XL and Suh Y: A common variant in pre-miR-146 is associated with coronary artery disease risk and its mature miRNA expression. Mutat Res 761: 15-20, 2014.

44. Hu Z, Chen X, Zhao Y, Tian T, Jin G, Shu Y, Chen Y, Xu L, Zen K, Zhang C, et al: Serum microRNA signatures identified in a genome-wide serum microRNA expression profiling predict survival of non-small-cell lung cancer. J Clin Oncol 28: 1721-1726, 2010

45. Wang J, Bi J, Liu X, Li K, Di J and Wang B: Hsa-miR-146a polymorphism (rs2910164) and cancer risk: A meta-analysis of 19 case-control studies. Mol Biol Rep 39: 4571-4579, 2012.

46. Catucci I, Yang R, Verderio P, Pizzamiglio S, Heesen L, Hemminki K, Sutter C, Wappenschmidt B, Dick M, Arnold N, et al: Evaluation of SNPs in miR-146a, miR196a2 and miR-499 as low-penetrance alleles in German and Italian familial breast cancer cases. Hum Mutat 31: E1052-E1057, 2010. 